\title{
A comparison of echocardiography to invasive measurement in the evaluation of pulmonary arterial hypertension in a rat model
}

\author{
Juha W. Koskenvuo $\cdot$ Rachel Mirsky $\cdot$ Yan Zhang • Franca S. Angeli • \\ Sarah Jahn - Tero-Pekka Alastalo • Nelson B. Schiller • Andrew J. Boyle • \\ Kanu Chatterjee $\cdot$ Teresa De Marco $\cdot$ Yerem Yeghiazarians
}

Received: 14 December 2009/ Accepted: 21 January 2010/Published online: 7 February 2010

(C) The Author(s) 2010. This article is published with open access at Springerlink.com

\begin{abstract}
Pulmonary arterial hypertension (PAH) is a life-threatening condition characterized by progressive elevation in pulmonary artery pressure (PAP) and total pulmonary vascular resistance (TPVR). Recent advances in imaging techniques have allowed the development of new echocardiographic parameters to evaluate disease progression. However, there are no reports comparing the diagnostic performance of these non-invasive parameters to each other and to invasive measurements. Therefore, we investigated the diagnostic yield of echocardiographically derived TPVR and Doppler parameters of PAP in screening and measuring the severity of PAH in a rat model. Serial echocardiographic and invasive measurements were performed at baseline, 21 and 35 days after monocrotaline-induction of PAH. The most challenging echocardiographic derived TPVR measurement had good correlation with the invasive measurement $(r=0.92, P<0.001)$ but also more simple and novel
\end{abstract}

J. W. Koskenvuo $(\bowtie) \cdot$ R. Mirsky · Y. Zhang ·

F. S. Angeli · S. Jahn · N. B. Schiller ·

A. J. Boyle - K. Chatterjee - T. De Marco ·

Y. Yeghiazarians

Division of Cardiology, Department of Medicine,

University of California, 505 Parnassus Avenue,

Box 0103, San Francisco, CA 94143, USA

e-mail: juhkos@utu.fi

T.-P. Alastalo

Department of Pediatrics, Stanford University School

of Medicine, Stanford, CA, USA parameters of TPVR were found to be useful although the non-invasive TPVR measurement was feasible in only $29 \%$ of the studies due to lack of sufficient tricuspid valve regurgitation. However, echocardiographic measures of PAP, pulmonary artery flow acceleration time (PAAT) and deceleration (PAD), were measurable in all animals, and correlated with invasive PAP $(r=-0.74$ and $r=0.75, P<0.001$ for both). Right ventricular thickness and area correlated with invasive PAP $(r=0.59$ and $r=0.64$, $P<0.001$ for both). Observer variability of the invasive and non-invasive parameters was low except in tissue-Doppler derived isovolumetric relaxation time. These non-invasive parameters may be used to replace invasive measurements in detecting successful disease induction and to complement invasive data in the evaluation of PAH severity in a rat model.

Keywords Pulmonary hypertension · Echocardiography · Monocrotaline · Total pulmonary vascular resistance . Pulmonary artery pressure $\cdot$ PAAT $\cdot$ PAD

\section{Introduction}

Pulmonary hypertension ( $\mathrm{PH})$ is a progressive and life threatening condition characterized by a progressive increase in pulmonary vascular resistance resulting in right heart failure and death. PH is classified in 
five subgroups according to etiology, of which one is pulmonary arterial hypertension (PAH) [1]. Prognosis in idiopathic $\mathrm{PH}$, a subgroup of $\mathrm{PAH}$, remains poor [2]. PAH is defined by a mean pulmonary artery pressure $(\mathrm{PAP})>25 \mathrm{mmHg}$ at rest or $>30 \mathrm{mmHg}$ during exercise [3]. Doppler echocardiography allows indirect measurement of PAP from valvular regurgitation and detects corresponding changes in right heart morphology and function [4-6]. In clinical practice, right heart catheterization is mandatory to confirm the presence of PAH and to test vasoreactivity of the pulmonary circulation [7].

Echocardiographically derived peak and mean PAP have been reported to correlate $(r=0.73-$ 0.94) with invasive measurements in humans [8-10]. However, these measurements require the presence of right-sided valvular regurgitation. Tricuspid valve regurgitation (TR) can be detected in only $39-86 \%$ of patients and in only $44-96 \%$ of these cases does the regurgitation produce enough signal for pressure measurement to be made possible [4]. Detecting a good signal from pulmonary valve regurgitation also requires technical competence but has approximately the same yield as TR signals [11]. Furthermore, PAP measurement without flow information can be misleading especially in cases with elevated PAP due to high cardiac output but normal pulmonary vascular resistance (PVR). Therefore, additional non-invasive parameters for evaluation of PAH are much needed.

Echocardiographically derived PVR has proven to be a valuable parameter [12, 13]. However, this measurement also requires the presence of TR. Tissue Doppler derived isovolumetric relaxation time (IVRT') of the right ventricle (RV) predicts elevated PAP in humans [14]. Pulmonary artery acceleration time (PAAT) correlated ( $r=0.84-0.89)$ with invasive PAP especially in mild to moderate PAH and was prognostic as well [15]. However, except for PAAT, all other measurements require acceptable Doppler image quality. Three different velocity profiles (normal round-shaped, intermediate and triangular) were characterized corresponding to the severity of PAH [16, 17] (Fig. 1). Under normal conditions, pulmonary artery flow velocity increases and decreases slowly and symmetrically. In PAH, flow velocity increases and decreases rapidly [18, 19] due to increased right ventricular stroke work and stiffness in the pulmonary artery leading to altered velocity profiles. The greatest difference in these flow

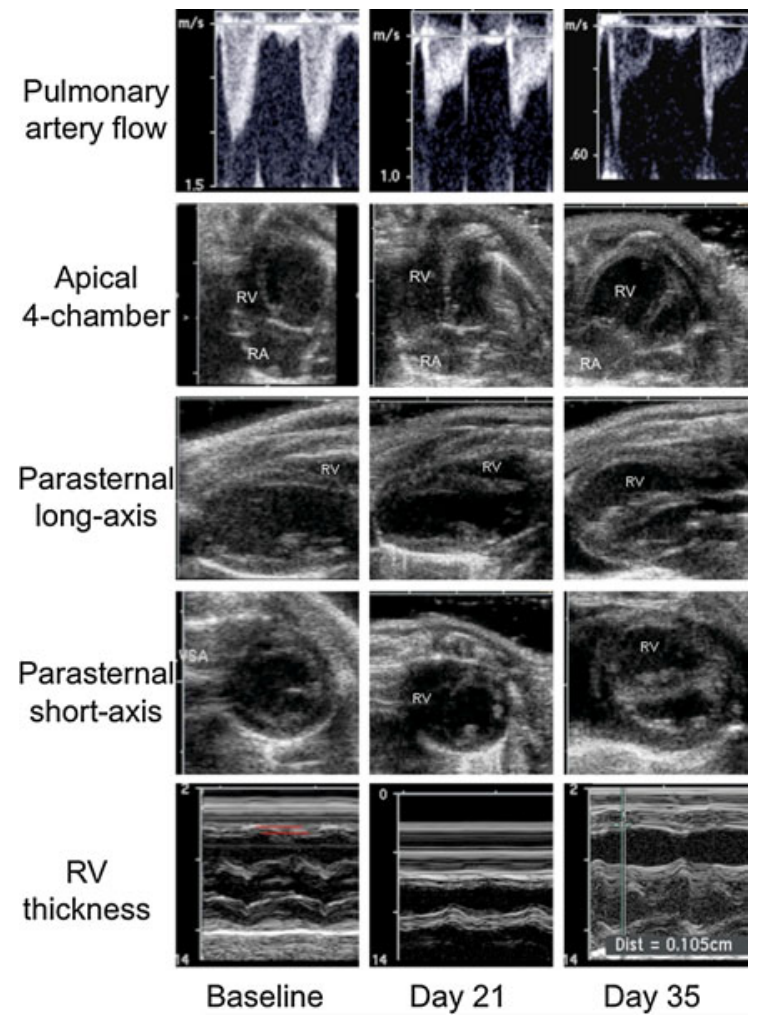

Fig. 1 Progression of PAH demonstrated by echocardiography at baseline, and 21 and 35 days after MCT induction. Columns represent temporal phases (baseline, day 21, and day 35) and rows five different imaging windows: (1) high parasternal short-axis view is used to detect pulmonary artery flow by pulsed-wave Doppler, right ventricular remodeling by (2) apical four-chamber view, (3) parasternal long-axis, (4) parasternal short-axis views using B-mode (all end-diastolic), and right ventricular thickness by (5) parasternal long-axis through aortic valve using M-mode. Upper row demonstrates different types of pulmonary artery flow profiles regarding to the severity of pulmonary hypertension. Normal, round-shaped flow profile (baseline), intermediate type flow profile with a sharp peak at early systole, decreased acceleration time and increased deceleration (day 21) and triangular flow profile with mid-systolic notching (day 35). Apical four-chamber and both parasternal views show progressive right ventricular dilatation with concomitant decrease of left ventricle. Parasternal longaxis images through aorta using M-mode show progressing right ventricular hypertrophy

profiles exists during the early deceleration period. However, it has not been shown whether quantification of the pulmonary artery flow deceleration (PAD) is useful for detecting PAH or measuring its severity. Furthermore, observer related variability of the invasive and noninvasive parameters of PAH in rats is relatively unknown. 
We investigated the diagnostic yield of echocardiographically derived TPVR and echocardiographic parameters of PAP in screening PAH in a rat model. Furthermore, we studied whether these non-invasive measurements can be used to measure the severity of PAH by comparing them to invasive measurements. We hypothesized that the echocardiographic parameters TPVR, IVRT', PAAT, PAD, right ventricular area and thickness reliably predict the severity of $\mathrm{PAH}$ and are reproducible.

\section{Methods}

Six-week old female RNU-1 (Charles river) nude rats ( $n=28)$ were used according to our protocol approved by Institutional animal care and use committee (IACUC). Pulmonary hypertension was induced using intraperitoneal injection of monocrotaline (MCT) (Sigma-Aldrich, St. Louis, MO) with a dose of $75 \mathrm{mg} / \mathrm{kg}$. MCT was dissolved in $\mathrm{HCl}$ (hydrochloric acid), diluted with distilled water and administered after adjusting the $\mathrm{pH}$ to 7.4. MCT is a pyrrolized alkaloid derived from Crotalia spectabilis and its administration into the intraperitoneal cavity is associated with increased pulmonary arterial pressure, increased medial wall thickening, and RV hypertrophy [20, 21]. The MCT-induced PAH model is widely used and has shown similarities to human idiopathic PAH $[22,23]$. Right heart catheterization and echocardiography were performed within the same day under general anesthesia (2\% isofluorane/ oxygen $11 / \mathrm{min}$ ). The animals were placed on a heating pad to maintain body temperature at $37-38^{\circ} \mathrm{C}$ throughout the studies. Studies were performed at baseline, 21 and 35 days after MCT injection.

Invasive measurements by right heart catheterization

Lidocaine $(6 \mathrm{mg} / \mathrm{kg})$ was administered subcutaneously into the neck of the animal and the right or left external jugular vein was isolated. A $2 \mathrm{~F}$ microtip catheter (Millar Instruments) was connected via a pressure control unit (Millar Instruments, Houston, TX) to a physiological recorder (Powerlab ML786) and viewed using Chart5 computer software (ADInstruments, Colorado Springs, CO). The catheter was guided into the RV to obtain pressure measurements after calibration. Pulmonary valve pathology was excluded at baseline using echocardiography and therefore right ventricular systolic pressure (RVSP) is similar to the systolic PAP. An average of 15-20 pressure cycles was utilized to obtain final pressure value. Systolic PAP values were employed to determine mean PAP using the following experimental formula: Mean PAP (in $\mathrm{mmHg}$ ) $=0.61$ *systolic PAP +2 [24]. Invasive TPVR in dyn $\cdot \mathrm{s} \cdot \mathrm{cm}^{-5}$ was calculated using the following formula: $80 *$ mean PAP (in $\mathrm{mmHg}$ )/cardiac output (in liters).

\section{Echocardiography}

Transthoracic echocardiography was performed by Sequoia C 256 ultrasound device (Acuson Inc., Mountain View, California) with a $15.0 \mathrm{MHz}$ linear or a 3.5 MHz cardiac transducer. Presence of TR was assessed from color Doppler images using a 15.0 MHz transducer. Tricuspid valve was graded as normal if TR was not observed, mild, moderate and severe when regurgitation jet was visually $<20 \%$, $20-50 \%$ or $>50 \%$ of the right atrial area, respectively. If TR was observed, the regurgitation velocity was assessed by using a $3.5 \mathrm{MHz}$ transducer with continuous wave Doppler. Pulmonary artery flow was measured using pulsed wave Doppler with a sample gate of $1.0 \mathrm{~mm}$ at pulmonary valve level but signal for PAAT and PAD measurements were achieved from the right ventricular outflow tract and opening and closing clicks of the pulmonary valve were avoided. By combining pulmonary artery velocitytime integral, pulmonary artery area and heart rate, echocardiographically derived cardiac output was determined as published earlier [25]. Tissue Doppler was measured from basal lateral wall of the right ventricle in a four-chamber view with a gate of 1-2 mm. Echo-TPVR was measured using four different ways: Echo-TPVR formula-1 (peak TR velocity/ right ventricular outflow tract velocity time integral (RVOT VTI)) [13], Echo-TPVR formula-2 (TPVR (in dyn $\cdot \mathrm{s} \cdot \mathrm{cm}^{-5}$ ) $=80 *$ mean PAP (in $\mathrm{mmHg}$ )/ cardiac output (in liters), in which mean PAP is determined from systolic PAP as outlined previously, Echo-TPVR formula-3 (PAAT/RVOT VTI), and Echo-TPVR formula-4 (PAD/RVOT VTI). IVRT' was defined as the interval from the end of $S_{m}$ wave to the beginning of $E_{a}$ wave [26]. PAAT was defined as the interval from the onset to the maximal velocity 
of forward pulmonary artery flow and PAD as the first linear deceleration period after maximal velocity. Right ventricular thickness was measured at diastole from parasternal long axis view using M-mode. Apical four-chamber view was employed to measure end-diastolic right ventricular area.

\section{Statistical analysis}

Statistical analysis was performed using either SPSS 16 (SSPP Inc, Chicago, IL, USA) or SAS (SAS Institute, Cary, NC, USA). Statistical difference between the parameters at baseline, 21 and 35 days after PAH induction was assessed with repeatedmeasures analysis of variance with Tukey's correction, except for those without successful measurements at baseline, which were assessed by paired $t$-test. Pearson or Spearman correlation coefficients were appropriately calculated. Bland-Altman method was used for comparing parameters when appropriate [27]. To obtain intraobserver and interobserver variability of the invasive and noninvasive parameters, ten studies were analyzed by two blinded reviewers. Observer variability is expressed using coefficient of variation $(\mathrm{CV})$, mean difference and intraclass correlation [28]. CV for repeated measurements was calculated by dividing SD with a mean and expressed as percentage values. Mean difference (\%) was calculated using the following formula (Imeasurement 1 - measurement 21$) /(($ measurement $1+$ measurement 2)/2)*100. ROC curves were generated to explore an optimal cut-off value of the studied parameters to discriminate animals with PAH from non-PAH animals. An area under each ROC curve (AUC) was calculated. Positive and negative predictive values, sensitivity, specificity and accuracy were calculated using standard formulas. $P$-value less than 0.05 was considered significant. The results are expressed as mean $\pm \mathrm{SD}$.

\section{Results}

A total of 75 echocardiographies were performed and analyzed in rats with variable degrees of PAP at the combined time-points of baseline, 21 and 35 days after MCT injection. Twenty-eight animals had echos performed at baseline and at 21 days. However, only 19 animals had the echocardiography at day 35 due to the mortality associated with significant PAH. Pulmonary artery flow (Fig. 1) was measured successfully by echocardiography in all animals whereas invasive PAP measurement was technically feasible in only 62 out of $75(83 \%)$ studies, mostly due to the technically challenging nature of accessing murine right ventricle in PAH. There was no detectable TR in any of the study animals at baseline. At day 35 , up to $84 \%$ of the animals had TR. Ten mild, ten moderate and 14 severe TR were noted in total. Detailed hemodynamic data is presented in Table 1 .

The correlation between echocardiographically derived TPVR with invasive TPVR measurements were as follows: $r=0.85, P<0.001, r=0.92$, $P<0.001, \quad r=0.08, \quad P=0.56$ and $r=0.70$, $P<0.001$ for Echo-TPVR formula 1, 2, 3 and 4, respectively (Fig. 2a, b). Echo-derived TPVR using formula 1 and 2 was measurable in only $23 \%$ (14 out of 62) of the studies with successful invasive measurements; the rest of the animals had an insufficient degree of TR for evaluation. Figure $2 \mathrm{c}$ demonstrates Bland-Altman plot between EchoTPVR formula-2 and invasive TPVR measurement. Additionally, one of the TPVR measurement pair is noted to be radically different than the others but the observed correlations between echo-TPVR-1 and 2 versus invasive-TPVR are $r=0.67, P=0.005$ and $r=0.70, P<0.001$, respectively, even after excluding this pair. The measurement of IVRT' had a weak correlation $(r=0.38, P=0.02)$ with invasive PAP and it was measurable in $56 \%$ of the studies. PAAT $(r=-0.74, \quad P<0.001)$ and PAD $(r=0.75$, $P<0.001)$ had relatively good correlations with invasive PAP (Fig. 3a, b). Even though echocardiographically derived systolic PAP had a minimal mean difference of $5.4 \pm 12.8 \mathrm{mmHg}$ compared to invasive PAP, significant correlation $(r=0.38$, $P=0.18$ ) was not observed between the methods due to small range of observed PAPs using this echo method. Both anatomical measures, right ventricular thickness and right ventricular area, correlated with invasive PAP $(r=0.59$ and $r=0.64, P<0.001$ for both).

Intraobserver and interobserver variabilities of the studied parameters are presented in Table 2. Intraobserver and interobserver variability of the invasive PAP expressed as coefficient of variation was $1.4 \pm 2.0$ and $1.3 \pm 1.4 \%$. The intraobserver and interobserver variability values for all the non- 
Table 1 Characteristics of rats at baseline and 21 and 35 days after MCT injection for induction of pulmonary arterial hypertension

\begin{tabular}{|c|c|c|c|c|c|c|}
\hline & $\begin{array}{l}\text { Baseline } \\
(n=28)\end{array}$ & $\begin{array}{l}\text { Day } 21 \\
(n=28)\end{array}$ & $\begin{array}{l}\text { Day } 35 \\
(n=19)\end{array}$ & $\begin{array}{l}\text { Baseline vs. } \\
\text { day } 21\end{array}$ & $\begin{array}{l}\text { Day } 21 \text { vs. } \\
\text { day } 35\end{array}$ & $\begin{array}{l}\text { Baseline vs. } \\
\text { day } 35\end{array}$ \\
\hline Weight (g) & $150.0 \pm 26.9$ & $170.9 \pm 18.0$ & $184.6 \pm 24.7$ & $P=0.04$ & $P=0.13$ & $P<0.001$ \\
\hline Heart rate $(\mathrm{bpm})$ & $373 \pm 32$ & $344 \pm 41$ & $304 \pm 43$ & $P=0.02$ & $P=0.002$ & $P<0.001$ \\
\hline Invasive systolic PAP (mmHg) & $29.6 \pm 3.7$ & $39.5 \pm 15.5$ & $65.3 \pm 14.9$ & $P=0.01$ & $P<0.001$ & $P<0.001$ \\
\hline Invasive mean PAP (mmHg) & $20.1 \pm 2.3$ & $26.1 \pm 9.5$ & $41.8 \pm 9.1$ & $P=0.01$ & $P<0.001$ & $P<0.001$ \\
\hline Invasive TPVR $\left(10^{4} * \mathrm{dyn} \cdot \mathrm{s} \cdot \mathrm{cm}^{-5}\right)$ & $2.3 \pm 0.8$ & $3.5 \pm 2.3$ & $6.4 \pm 3.9$ & $P=0.24$ & $P<0.01$ & $P<0.001$ \\
\hline Tricuspid regurgitation (\%) & $0 \%$ & $64 \%$ & $84 \%$ & $P<0.001$ & $P=0.15$ & $P<0.001$ \\
\hline Echo systolic PAP (mmHg) & NA & $66.4 \pm 18.8$ & $83.6 \pm 16.2$ & NA & $P=0.03$ & NA \\
\hline Echo TPVR $\left(\mathrm{ms}^{-1} \mathrm{~m}\right)$ & NA & $142 \pm 61$ & $149 \pm 60$ & NA & $P=0.57$ & NA \\
\hline Echo TPVR $\left(10^{4} *\right.$ dyn $\left.\cdot \mathrm{s} \cdot \mathrm{cm}^{-5}\right)$ & NA & $7.7 \pm 2.8$ & $9.2 \pm 5.9$ & NA & $P=0.52$ & NA \\
\hline IVRT’'(ms) & $20.2 \pm 9.4$ & $20.1 \pm 16.9$ & $29.0 \pm 18.3$ & $P=1.00$ & $P=0.29$ & $P=0.29$ \\
\hline Pulmonary artery acceleration time (ms) & $36.3 \pm 5.5$ & $27.7 \pm 6.3$ & $21.7 \pm 4.5$ & $P<0.001$ & $P<0.01$ & $P<0.001$ \\
\hline Pulmonary artery deceleration $\left(\mathrm{m} / \mathrm{s}^{2}\right)$ & $7.3 \pm 2.4$ & $11.7 \pm 6.6$ & $16.6 \pm 4.7$ & $P<0.01$ & $P<0.01$ & $P<0.001$ \\
\hline Right ventricular cardiac output (ml) & $77.7 \pm 20.6$ & $65.5 \pm 21.8$ & $63.0 \pm 22.8$ & $P=0.12$ & $P=0.93$ & $P=0.08$ \\
\hline Right ventricular area $\left(\mathrm{cm}^{2}\right)$ & $0.18 \pm 0.04$ & $0.26 \pm 0.09$ & $0.31 \pm 0.10$ & $P=0.02$ & $P<0.001$ & $P<0.001$ \\
\hline Right ventricular thickness (mm) & $0.42 \pm 0.07$ & $0.55 \pm 0.17$ & $0.77 \pm 0.18$ & $P=0.02$ & $P=0.10$ & $P<0.001$ \\
\hline
\end{tabular}

All data is presented as mean $\pm \mathrm{SD}$

See Methods for calculations

$P A P$ pulmonary artery pressure; TPVR total pulmonary vascular resistance; $N A$ not available; IVRT' tissue Doppler derived isovolumetric relaxation time of the right ventricle
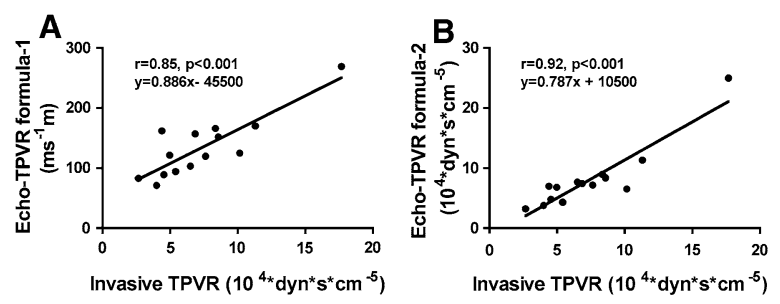

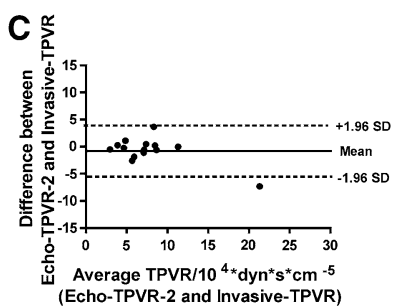

cardiac output in liters) (b). Invasive TPVR was calculated using the previous formula and the mean PAP was derived from systolic PAP using previously validated formula [24], and Bland-Altman plot between Echo-TPVR formula-2 and invasive TPVR measurement (c)

0.943 ) for PAAT, $11.8 \mathrm{~m} / \mathrm{s}^{2}$ (AUC 0.931) for PAD, $0.56 \mathrm{~mm}$ (AUC 0.887) for RV thickness and $0.225 \mathrm{~cm}^{2}$ (AUC 0.907) for RV area, respectively. PAAT $<28 \mathrm{~ms}$ had the best diagnostic value when accounting all non-invasive parameters. We created two new algorithms of pulmonary flow by combining PAAT $<28 \mathrm{~ms}$ and PAD $>11.8 \mathrm{~m} / \mathrm{s}^{2}$ values (Table 3). The algorithm of PAAT $<28 \mathrm{~ms}$ and PAD $>11.8 \mathrm{~m} / \mathrm{s}^{2}$ has the best specificity of $97.3 \%$ and PAAT $<28 \mathrm{~ms}$ has the best sensitivity of $86.4 \%$. 
Fig. 3 Correlation between invasive (right heart catheterization) measurement of PAP and its estimation from echocardiographically derived pulmonary artery acceleration time (a) and pulmonary artery deceleration (b)
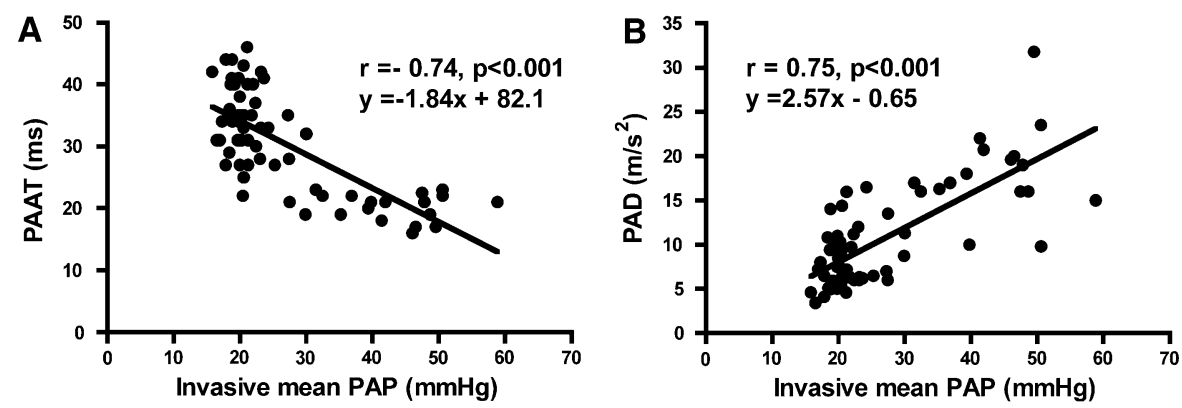

Table 2 Intraobserver and interobserver variability of the invasive and noninvasive parameters of pulmonary arterial hypertension

\begin{tabular}{|c|c|c|c|}
\hline & $\mathrm{CV} \%$ & $\begin{array}{l}\text { Mean difference } \\
\text { (range) } \%\end{array}$ & $\begin{array}{l}\text { Intraclass correlation } \\
(P \text {-value })\end{array}$ \\
\hline \multicolumn{4}{|l|}{ Intraobserver variability } \\
\hline Invasive mean PAP (mmHg) & $1.4 \pm 2.0$ & $1.3(-6.4-2.4)$ & $0.99(P<0.001)$ \\
\hline Invasive TPVR $\left(10^{4} * \mathrm{dyn} \cdot \mathrm{s} \cdot \mathrm{cm}^{-5}\right)$ & $7.2 \pm 9.3$ & $12.3(-10.7-25.4)$ & $0.90(P<0.001)$ \\
\hline Echo systolic PAP (mmHg) & $4.9 \pm 3.3$ & $4.6(-10.8-7.9)$ & $0.97(P<0.001)$ \\
\hline Echo TPVR $\left(\mathrm{ms}^{-1} \mathrm{~m}\right)$ & $5.8 \pm 4.6$ & $5.4(-8.0-14.7)$ & $0.95(P<0.001)$ \\
\hline Echo TPVR $\left(10^{4} *\right.$ dyn $\left.\cdot \mathrm{s} \cdot \mathrm{cm}^{-5}\right)$ & $10.1 \pm 12.2$ & $9.5(-24.2-31.0)$ & $0.85(P<0.001)$ \\
\hline IVRT’ (ms) & $7.6 \pm 7.0$ & $8.1(-13.1-15.2)$ & $0.96(P<0.001)$ \\
\hline PAAT (ms) & $4.8 \pm 3.0$ & $4.6(-7.5-6.6)$ & $0.90(P<0.001)$ \\
\hline $\operatorname{PAD}\left(\mathrm{m} / \mathrm{s}^{2}\right)$ & $10.2 \pm 6.7$ & $9.9(-23.5-9.5)$ & $0.94(P<0.001)$ \\
\hline Right ventricular area $\left(\mathrm{cm}^{2}\right)$ & $11.3 \pm 9.4$ & $8.8(-18.3-16.4)$ & $0.90(P<0.001)$ \\
\hline Right ventricular thickness (mm) & $8.1 \pm 7.2$ & $5.2(-16.1-13.2)$ & $0.95(P<0.001)$ \\
\hline \multicolumn{4}{|l|}{ Interobserver variability } \\
\hline Invasive mean PAP (mmHg) & $1.3 \pm 1.4$ & $1.3(-1.8-3.7)$ & $1.00(P<0.001)$ \\
\hline Invasive TPVR $\left(10^{4} * \mathrm{dyn} \cdot \mathrm{s} \cdot \mathrm{cm}^{-5}\right)$ & $9.1 \pm 8.6$ & $8.4(-16.6-24.6)$ & $0.94(P<0.001)$ \\
\hline Echo systolic PAP (mmHg) & $3.6 \pm 3.6$ & $3.3(-4.1-9.7)$ & $0.98(P<0.001)$ \\
\hline Echo TPVR $\left(\mathrm{ms}^{-1} \mathrm{~m}\right)$ & $4.9 \pm 1.3$ & $4.6(-5.4-7.3)$ & $0.98(P<0.001)$ \\
\hline Echo TPVR $\left(10^{4} *\right.$ dyn $\left.\cdot \mathrm{s} \cdot \mathrm{cm}^{-5}\right)$ & $9.7 \pm 8.5$ & $9.0(-18.4-20.7)$ & $0.95(P<0.001)$ \\
\hline IVRT’'(ms) & $20.6 \pm 27.2$ & $22.2(-84.6-16.0)$ & $0.89(P<0.001)$ \\
\hline PAAT (ms) & $2.6 \pm 3.5$ & $2.4(-4.1-9.1)$ & $0.93(P<0.001)$ \\
\hline $\operatorname{PAD}\left(\mathrm{m} / \mathrm{s}^{2}\right)$ & $5.8 \pm 5.4$ & $5.3(-7.0-14.0)$ & $0.98(P<0.001)$ \\
\hline Right ventricular area $\left(\mathrm{cm}^{2}\right)$ & $11.2 \pm 9.3$ & $9.0(-14.3-16.2)$ & $0.91(P<0.001)$ \\
\hline Right ventricular thickness (mm) & $8.9 \pm 8.6$ & $5.9(-15.6-18.3)$ & $0.95(P<0.001)$ \\
\hline
\end{tabular}

Values for coefficient of variation $(\mathrm{CV})$ are means \pm SD and for mean difference are means and range

See Methods for calculations

$P A P$ pulmonary artery pressure; TPVR total pulmonary vascular resistance; $I V R T$ ' tissue Doppler derived isovolumetric relaxation time of the right ventricle; $P A A T$ pulmonary artery acceleration time; $P A D$ pulmonary artery deceleration

\section{Discussion}

We have demonstrated that pulmonary artery flow is readily detectable using echocardiography and can be used as a screening tool for the evaluation of PAH in a rat model. Furthermore, we have shown that parameters such as echo-TPVR, PAAT, and PAD are associated with the severity of PAH. Since rat models are increasingly used in studies evaluating various therapeutic interventions for $\mathrm{PAH}$, these non-invasive parameters allow identification and quantification of disease progression at multiple time-points, replacing or at least complementing invasive data. Furthermore, we have developed 
Table 3 Diagnostic performance of echocardiographic parameters to detect pulmonary hypertension $(\mathrm{mPAP}>25 \mathrm{mmHg})$

\begin{tabular}{|c|c|c|c|c|c|c|}
\hline & $\begin{array}{l}\text { PAAT } \\
<28 \mathrm{~ms}(\%)\end{array}$ & $\begin{array}{l}\text { PAD } \\
>11.8 \mathrm{~m} / \mathrm{s}^{2}(\%)\end{array}$ & $\begin{array}{l}\text { PAAT }<28 \mathrm{~ms} \text { and } \\
\text { PAD }>11.8 \mathrm{~m} / \mathrm{s}^{2}(\%)\end{array}$ & $\begin{array}{l}\text { PAAT }<28 \mathrm{~ms} \text { or } \\
\text { PAD }>11.8 \mathrm{~m} / \mathrm{s}^{2} \\
(\%)\end{array}$ & $\begin{array}{l}\mathrm{RV} \text { thickness } \\
>0.56 \mathrm{~mm}(\%)\end{array}$ & $\begin{array}{l}\mathrm{RV} \text { area } \\
>0.225 \mathrm{~cm}^{2}(\%)\end{array}$ \\
\hline Sensitivity & 86.4 & 72.7 & 68.2 & 86.4 & 72.7 & 82.6 \\
\hline Specificity & 87.8 & 87.8 & 97.6 & 78.0 & 94.3 & 84.6 \\
\hline $\begin{array}{l}\text { Negative } \\
\text { predictive } \\
\text { value }\end{array}$ & 79.2 & 76.2 & 93.8 & 67.9 & 88.9 & 76.0 \\
\hline $\begin{array}{l}\text { Positive } \\
\text { predictive } \\
\text { value }\end{array}$ & 92.3 & 85.7 & 85.1 & 91.4 & 84.6 & 89.2 \\
\hline Accuracy & 87.3 & 82.5 & 87.3 & 81.0 & 86.0 & 83.9 \\
\hline
\end{tabular}

See Methods for calculations

$P A A T$ pulmonary artery acceleration time; $P A D$ pulmonary artery deceleration; $P A P$ pulmonary artery pressure; $R V$ right ventricle

algorithms for the evaluation of PAH that may also have value in the evaluation of PAH in patients.

Invasive PAPs in our study were similar to the values reported in earlier studies of rats with MCTinduced PAH [20, 29, 30]. Distinction to the high yield of non-invasive echocardiography methods, we measured invasive PAP successfully in only 34 out of 47 cases $(72 \%)$ with advanced PAH. This experience is in-line with the success rates reported by other investigators: $80 \%$ at day 21 and $50 \%$ at day 35 (personal communication, Dr Hirofumi Sawada, Stanford University, CA). The difficulty of performing invasive measurements in animals with advanced $\mathrm{PAH}$ is an important limitation of all invasive parameters and underscores the importance of innovative non-invasive measurements.

To our knowledge, TPVR has not been studied in rodents using echocardiography. In our study, echoTPVR values predicted invasive TPVR values but were limited to animals with more advanced PAH with TR jet. Echo-TPVRs were studied only to check whether their use would offer relevant and easily detectable information in this animal model. Both Echo-TPVR formulas 1 and 4, which are simpler measurements, were found to be useful when compared to the diagnostic yield of echo-TPVR formula2 , which is a more complex calculation.

We found tissue Doppler parameter difficult to measure. This failure may be explained by the fact that rats have a much thinner right ventricular wall and a higher heart rate than humans. Additionally, we noticed that Doppler gain settings have a significant influence on IVRT' values. Only 2-4 ms difference in IVRT' corresponds to $10-20 \%$ change in this parameter. IVRT' values corrected to RR-interval were similar to the levels observed by Boissiere et al. [26] (data not shown). Recently, it has been reported that IVRT' $<40$ ms has $100 \%$ negative predictive value for PAH in humans [14]. Furthermore, IVRT' is generally a measure of right ventricular diastolic function describing ventricular burden of PAH. Therefore, it has substantial limitations for use in the measurement of PAH. Other ultrasound systems with different filtering algorithms for tissue Doppler signals may have led to better diagnostic yield of tissue Doppler technique but this remains to be studied.

Pulmonary artery acceleration time values in our study were similar to the values observed in earlier studies of rats with MCT-induced PAH [30, 31]. Jones et al. [30] reported the correlation of 0.84 between PAAT and invasive PAP only in animals with PAAT between 20 and $32 \mathrm{~ms}$. In our study a comparable correlation was found even without excluding values outside this range. Short PAAT values are likely due to reduced capacitance and the increased impedance of the pulmonary vascular bed causing the deceleration to begin at early systole [32]. Furthermore, increased stiffness of pulmonary artery may cause short PAAT and rapid PAD by increasing the pulse wave velocity and therefore causing earlier reflection from the periphery resulting in early deceleration [33].

Previously, Jones et al. [30] showed that quantification of TR velocity is usually unsuccessful in rats 
with systolic PAP below $65 \mathrm{mmHg}$. Our data supports this observation, as we were able to quantify TR velocity from only one rat with invasive systolic PAP below $65 \mathrm{mmHg}$. Jones et al. [30] also demonstrated a good correlation $(r=0.92)$ between rat PAP using this method compared to invasive measurement, but the technique succeeded only in six of 61 animals. In our study, the lack of significant correlation between TR velocity derived PAP compared to invasive PAP may be explained by the relatively small range of successful PAP measurements by this particular echo technique. No other studies have evaluated intra- or interobserver variabilities of the invasive PAP or TPVR measurement in the rat model of PAH. Jones et al. [30] reported the intraobserver and interobserver variability between 3.0 and $3.5 \%$ for PAAT by a non-standard method of using twice SD. In our report, all the echocardiographic parameters were found to have low intraobserver and interobserver variability. The exception was IVRT', which had a high interobserver variability and also the quite poor correlation with invasive PAP.

The algorithm of PAAT $<28 \mathrm{~ms}$ and PAD $>11.8 \mathrm{~m} / \mathrm{s}^{2}$ has the best specificity of $97.6 \%$ and the algorithm of PAAT $<28 \mathrm{~ms}$ or PAD $>11.8 \mathrm{~m} / \mathrm{s}^{2}$ has the best sensitivity of $82.6 \%$ of the studied parameters to detect significant PAH (of note, PAAT alone also has the same sensitivity). Parameter with a high sensitivity is advantageous for detecting established disease before treatment and parameter with a high specificity for excluding animals before further experiments due to failure in the induction of the disease. This is a critical issue in translational studies, as they are usually performed using relatively small treatment groups and are therefore, especially vulnerable for misleading results. The presented algorithms can be employed to ensure disease induction and improve the verity of the data collected.

There are a number of limitations to our study. First, echo-TPVR-formula-2 and invasive-TPVR were both calculated by cardiac outputs derived from noninvasive method. In this regard, it should be highlighted that the purpose of this study was to evaluate whether simple echocardiographic measurements such as those used for the calculation of echo-TPVR-1, 3 and 4 would have value when evaluating rat PAH. Based on our previous published work [25] noninvasive cardiac output was comparable to the invasive measurement. Additionally, it is well recognized that the presence of moderate to severe TR, as observed in advanced $\mathrm{PAH}$, may lead to inaccurate invasive thermodilution derived cardiac outputs whereas TR has no effect on the echocardiographically derived measurements and this may be preferable as an easier, more reproducible and non-invasive measure of cardiac output. Bland-Altman plots from two recent studies indicate that there may be more differences between thermodilution and Fick methods derived cardiac outputs compared to echocardiography and Fick $[34,35]$. Despite this, we do recognize this point as a limitation of our manuscript but do not believe that the invasive measurements would have altered the results of our findings and in fact, since it is very challenging to make these measurements in rats with significant PAH, we propose that future studies use the non-invasive method proposed here to avoid high animal mortality and allow completion of the research studies in a timely and cost-effective manner. Second, agitated saline or contrast agent was not used to enhance the Doppler signal determining TR velocity, which might have improved yield of successful measurements. However, contrast agents in rats require tail vein cannulation and a separate infusion pump with agitation capability, and importantly it would have potentially influenced the non-invasive nature of our measurements. Third, a correction for heart rate in PAAT measurement was not used. Finally, echocardiographically determined TPVR (formula 1) was not adjusted for right ventricular outflow tract diameter. However, in another study, this correction did not lead to a significant change in the correlation between the methods ( $r=0.73$ vs. $r=0.71$ ) [13].

In addition, it should be noted that the BlandAltman technique is considered ideal when evaluating agreement between two methods especially when one is comparing measurements, which are expected to give the same values in the ideal situation when the methods do not differ. In our study, only two variables were suitable for assessment with the Bland-Altman method, and this has been reported.

Finally, it should be emphasized that observed values of echocardiographic parameters in this study can be assumed valid only in rats. It has been shown that PAAT values are much higher in humans compared to rats due to lower heart rate [36]. PAP was measured only in animals with chronic pulmonary hypertension, and our results may not apply to acute PAH. 


\section{Conclusion}

In conclusion, we have shown that non-invasive echocardiography allows the measurement of several highly reproducible parameters for evaluation of PAH in a small animal model of which pulmonary artery acceleration time and deceleration are the most practical.

Acknowledgments This study was supported by a grant from The Foundation for Cardiac Research (KC, TDM and YY) The Harold Castle Foundation (to YY), The Cardiac Stem Cell Foundation (to YY) and all the following grants to JWK: Sigrid Juselius Foundation, Finnish Foundation for Cardiovascular Research, Paavo Nurmi Foundation, Varsinais-Suomi Regional Fund of Finnish Cultural Foundation and The Finnish Medical Foundation.

Open Access This article is distributed under the terms of the Creative Commons Attribution Noncommercial License which permits any noncommercial use, distribution, and reproduction in any medium, provided the original author(s) and source are credited.

\section{References}

1. Simonneau G, Robbins IM, Beghetti M, Channick RN, Delcroix M, Denton CP, Elliott CG, Gaine SP, Gladwin MT, Jing ZC, Krowka MJ, Langleben D, Nakanishi N, Souza R (2009) Updated clinical classification of pulmonary hypertension. J Am Coll Cardiol 54:S43-S54

2. D’Alonzo GE, Barst RJ, Ayres SM, Bergofsky EH, Brundage BH, Detre KM, Fishman AP, Goldring RM, Groves BM, Kernis JT (1991) Survival in patients with primary pulmonary hypertension. Results from a national prospective registry. Ann Intern Med 115:343-349

3. Galie N, Hoeper MM, Humbert M, Torbicki A, Vachiery JL, Barbera JA et al (2009) Guidelines for the diagnosis and treatment of pulmonary hypertension: the task force for the diagnosis and treatment of pulmonary hypertension of the European society of cardiology (ESC) and the European respiratory society (ERS), endorsed by the International society of heart and lung transplantation (ISHLT). Eur Heart J 30:2493-2537

4. Celermajer DS, Marwick T (2008) Echocardiographic and right heart catheterization techniques in patients with pulmonary arterial hypertension. Int J Cardiol 125:294-303

5. Cacciapuoti F (2009) Echocardiographic evaluation of right heart function and pulmonary vascular bed. Int $\mathrm{J}$ Cardiovasc Imaging 25:689-697

6. Willens HJ, Fertel DP, Qin J, Labrador E, Lowery MH (2008) Effects of age and pulmonary arterial hypertension on the different phases of right atrial function. Int $\mathrm{J}$ Cardiovasc Imaging 24:703-710

7. McGoon M, Gutterman D, Steen V, Barst R, McCrory DC, Fortin TA, Loyd JE, American college of chest physicians (2004) Screening, early detection, and diagnosis of pulmonary arterial hypertension: ACCP evidence-based clinical practice guidelines. Chest 126:14S-34S

8. Abbas AE, Fortuin FD, Schiller NB, Appleton CP, Moreno CA, Lester SJ (2003) Echocardiographic determination of mean pulmonary artery pressure. Am J Cardiol 92: 1373-1376

9. Bossone E, Bodini BD, Mazza A, Allegra L (2005) Pulmonary arterial hypertension: the key role of echocardiography. Chest 127:1836-1843

10. Selimovic N, Rundqvist B, Bergh CH, Andersson B, Petersson S, Johansson L, Bech-Hanssen O (2007) Assessment of pulmonary vascular resistance by Doppler echocardiography in patients with pulmonary arterial hypertension. J Heart Lung Transplant 26:927-934

11. Ristow B, Ali S, Ren X, Whooley MA, Schiller NB (2007) Elevated pulmonary artery pressure by Doppler echocardiography predicts hospitalization for heart failure and mortality in ambulatory stable coronary artery disease: the heart and soul study. J Am Coll Cardiol 49:43-49

12. Abbas AE, Fortuin FD, Schiller NB, Appleton CP, Moreno CA, Lester SJ (2003) A simple method for noninvasive estimation of pulmonary vascular resistance. J Am Coll Cardiol 41:1021-1027

13. Vlahos AP, Feinstein JA, Schiller NB, Silverman NH (2008) Extension of Doppler-derived echocardiographic measures of pulmonary vascular resistance to patients with moderate or severe pulmonary vascular disease. J Am Soc Echocardiogr 21:711-714

14. Brechot N, Gambotti L, Lafitte S, Roudaut R (2008) Usefulness of right ventricular isovolumic relaxation time in predicting systolic pulmonary artery pressure. Eur $\mathbf{J}$ Echocardiogr 9:547-554

15. Kjaergaard J, Schaadt BK, Lund JO, Hassager C (2009) Prognostic importance of quantitative echocardiographic evaluation in patients suspected of first non-massive pulmonary embolism. Eur J Echocardiogr 10:89-95

16. Kitabatake A, Inoue M, Asao M, Masuyama T, Tanouchi J, Morita T, Mishima M, Uematsu M, Shimazu T, Hori M, Abe H (1983) Noninvasive evaluation of pulmonary hypertension by a pulsed Doppler technique. Circulation 68:302-309

17. Okamoto M, Miyatake K, Kinoshita N, Sakakibara H, Nimura Y (1984) Analysis of blood flow in pulmonary hypertension with the pulsed Doppler flowmeter combined with cross sectional echocardiography. Br Heart $\mathrm{J}$ 51: 407-415

18. Martin-Duran R, Larman M, Trugeda A, Vazquez de Prada JA, Ruano J, Torres A, Figueroa A, Pajaron A, Nistal F (1986) Comparison of Doppler-determined elevated pulmonary arterial pressure with pressure measured at cardiac catheterization. Am J Cardiol 57:859-863

19. Isobe M, Yazaki Y, Takaku F, Koizumi K, Hara K, Tsuneyoshi H, Yamaguchi T, Machii K (1986) Prediction of pulmonary arterial pressure in adults by pulsed Doppler echocardiography. Am J Cardiol 57:316-321

20. Meyrick B, Gamble W, Reid L (1980) Development of Crotalaria pulmonary hypertension: hemodynamic and structural study. Am J Physiol 239:H692-H702

21. Buermans HP, Redout EM, Schiel AE, Musters RJ, Zuidwijk M, Eijk PP, van Hardeveld C, Kasanmoentalib S, Visser FC, Ylstra B, Simonides WS (2005) Microarray 
analysis reveals pivotal divergent mRNA expression profiles early in the development of either compensated ventricular hypertrophy or heart failure. Physiol Genomics 21:314-323

22. Ghodsi F, Will JA (1981) Changes in pulmonary structure and function induced by monocrotaline intoxication. Am J Physiol 240:H149-H155

23. White RJ, Meoli DF, Swarthout RF, Kallop DY, Galaria II, Harvey JL, Miller CM, Blaxall BC, Hall CM, Pierce RA, Cool CD, Taubman MB (2007) Plexiform-like lesions and increased tissue factor expression in a rat model of severe pulmonary arterial hypertension. Am J Physiol Lung Cell Mol Physiol 293:L583-L590

24. Chemla D, Castelain V, Humbert M, Hebert JL, Simonneau G, Lecarpentier Y, Herve P (2004) New formula for predicting mean pulmonary artery pressure using systolic pulmonary artery pressure. Chest 126:1313-1317

25. Penttilä J, Snapir A, Kentala E, Koskenvuo J, Posti J, Scheinin M, Scheinin H, Kuusela T (2006) Estimation of cardiac output in a pharmacological trial using a simple method based on arterial blood pressure signal waveform: a comparison with pulmonary thermodilution and echocardiographic methods. Eur J Clin Pharmacol 62:401-407

26. Boissiere J, Gautier M, Machet MC, Hanton G, Bonnet P, Eder V (2005) Doppler tissue imaging in assessment of pulmonary hypertension-induced right ventricle dysfunction. Am J Physiol Heart Circ Physiol 289:H2450-H2455

27. Bland JM, Altman DG (1986) Statistical methods for assessing agreement between two methods of clinical measurement. Lancet 1:307-310

28. Shrout PE, Fleiss JL (1979) Intraclass correlations: uses in assessing rater reliability. Psychol Bull 86:420-428

29. Hessel MH, Steendijk P, den Adel B, Schutte CI, van der Laarse A (2006) Characterization of right ventricular function after monocrotaline-induced pulmonary hypertension in the intact rat. Am J Physiol Heart Circ Physiol 291:H2424-H2430

30. Jones JE, Mendes L, Rudd MA, Russo G, Loscalzo J, Zhang YY (2002) Serial noninvasive assessment of progressive pulmonary hypertension in a rat model. Am $\mathbf{J}$ Physiol Heart Circ Physiol 283:H364-H371

31. McMurtry MS, Moudgil R, Hashimoto K, Bonnet S, Michelakis ED, Archer SL (2007) Overexpression of human bone morphogenetic protein receptor 2 does not ameliorate monocrotaline pulmonary arterial hypertension. Am J Physiol Lung Cell Mol Physiol 292:L872-L878

32. Reuben SR (1971) Compliance of the human pulmonary arterial system in disease. Circ Res 29:40-50

33. Milnor WR, Conti CR, Lewis KB, O'Rourke MF (1969) Pulmonary arterial pulse wave velocity and impedance in man. Circ Res 25:637-649

34. Fisher MR, Forfia PR, Chamera E, Housten-Harris T, Champion HC, Girgis RE, Corretti MC, Hassoun PM (2009) Accuracy of Doppler echocardiography in the hemodynamic assessment of pulmonary hypertension. Am J Respir Crit Care Med 179:615-621

35. Hoeper MM, Maier R, Tongers J, Niedermeyer J, Hohlfeld JM, Hamm M, Fabel H (1999) Determination of cardiac output by the Fick method, thermodilution, and acetylene rebreathing in pulmonary hypertension. Am J Respir Crit Care Med 160:535-541

36. Scapellato F, Temporelli PL, Eleuteri E, Corra U, Imparato A, Giannuzzi P (2001) Accurate noninvasive estimation of pulmonary vascular resistance by Doppler echocardiography in patients with chronic failure heart failure. J Am Coll Cardiol 37:1813-1819 